Gerión. Revista de Historia Antigua

ISSN: 0213-0181

http://dx.doi.org/10.5209/geri.71948

\title{
Epigrafía romana de Acinippo (Ronda la Vieja, Málaga): la documentación gráfica de Antonio Madrid Muñoz ${ }^{1}$
}

\author{
María del Rosario Hernando Sobrino²
}

Recibido: 3 de mayo de 2020 / Aceptado: 21 de junio de 2020

Resumen. Analizamos en este trabajo unos documentos gráficos relativos a diversas inscripciones de Acinippo (Ronda la Vieja, Málaga) conservados en la Real Academia de la Historia (Madrid). Estos documentos (dos láminas de dibujos y una fotografía) formaban parte del material que complementaba la "Memoria" que, sobre dicho lugar, escribió el cronista rondeño Antonio Madrid Muñoz; sin embargo, no llegaron a incluirse en la publicación de la misma, que vio la luz en 1913, privando a la comunidad científica de unos datos de gran interés para la correcta valoración de los epígrafes en ella registrados.

Palabras clave: inscripciones romanas; manuscritos; historiografía; Real Academia de la Historia.

\section{[en] Roman Epigraphy of Acinippo (Ronda la Vieja, Málaga): Antonio Madrid Muñoz's Graphic Documentation}

\begin{abstract}
We analyze in this paper some graphic documents, concerning to various inscriptions of Acinippo (Ronda la Vieja, Málaga) preserved at the Real Academia de la Historia (Madrid). These documents (two sheets of drawings and a photograph) were part of the material that complemented the "Memory" that Antonio Madrid Muñoz, chronicler of Ronda, wrote about this place. However, they were not included in the final version of the "Memory" -published in 1913- depriving the scientific community of interesting data for the correct evaluation of the epigraphs registered in it.
\end{abstract}

Keywords: Roman Inscriptions; Manuscripts; Historiography; Real Academia de la Historia.

Sumario: 1. Introducción. 2. Los epígrafes anotados por Antonio Madrid Muñoz. 2.1. El epígrafe conservado en el pavimento de la entrada del cortijo de Ronda la Vieja. 2.2. El epígrafe hallado en el

1 Este trabajo se enmarca en los proyectos de investigación Redes AVIPES-CM (ref. H2019-HUM/5742), de la Comunidad de Madrid/Fondo Social Europeo, Nuevas bases documentales para el estudio histórico de la Hispania romana en época republicana: onomástica y latinidad (III-I a.C.) (ref. HAR2015-66463-P), del Ministerio de Economía y Competitividad, y Corpus de Manuscritos de la Biblioteca Nacional de Madrid para la Historia Antigua de España (ref. PID2019-109530GB), del Ministerio de Ciencia, Innovación y Universidades, así como en los Grupos de investigación de la UCM Ciudades Romanas (ref. 930692) y TEAPIMeG (ref. 930750). Agradecemos a la Real Academia de la Historia las facilidades ofrecidas para el estudio y reproducción de las imágenes que acompañan y completan este trabajo. Del mismo modo, expresamos nuestra gratitud a los Dres. Joaquín Gómez-Pantoja † y Enrique Melchor, cuyas sugerencias y comentarios han contribuido a enriquecer estas líneas. Gracias también a la generosa ayuda de Joaquín, a cuya memoria dedicamos estas páginas, hemos podido ofrecer aquí unas fotografías más claras y legibles.

2 Universidad Complutense de Madrid - Archivo Epigráfico de Hispania.

E-mail: mrhernando@ghis.ucm.es

ORCID: 0000-0002-7509-7877 
Arrabal de Ronda la Vieja. 2.3. Un epígrafe más relacionado con M. Iunius Terentianus. 2.4. El epígrafe funerario de L. Aemilius. 3. Referencias bibliográficas.

Cómo citar: Hernando Sobrino, Ma R. (2020): Epigrafía romana de Acinippo (Ronda la Vieja, Málaga): la documentación gráfica de Antonio Madrid Muñoz, en Gerión 38/2, 563-583.

\section{Introducción}

La revisión de los fondos documentales atesorados en las diversas instituciones culturales constituye una tarea sobre cuya necesidad, a efectos de completar el conocimiento relativo al patrimonio histórico en sus múltiples facetas, no es necesario incidir. Para el ámbito de la epigrafía romana de Hispania, que es el tema que aquí se tratará, los frutos que tal revisión ha dado en las últimas décadas no hacen sino poner de relieve tal necesidad.

Especialmente generosos han sido, a este respecto, los fondos de la Real Academia de la Historia que, gracias a la paciente labor de un nutrido equipo de profesores e investigadores, se encuentran perfectamente organizados $\mathrm{y}$, en consecuencia, accesibles, para todos los interesados en la Antigüedad hispana. Y es que ha sido precisamente la obra Manuscritos sobre Antigüedades de la Real Academia de la Historia, editada por los doctores Juan Manuel Abascal y Rosario Cebrián, la que nos ha facilitado la detección y consiguiente acceso a unos documentos que creemos merecen, por ser conocidos sólo parcialmente, revisitarse aquí: nos referimos a los registrados con la signatura 9-7475-1 y 2, obra de Antonio Madrid Muñoz, datados ca. 1913 y titulados: Acinipo. Números 1 y 2. Dibujos complementarios. ${ }^{3}$

Ambos documentos se relacionan con la "Memoria" que el propio Madrid Muñoz (Fig. 1), correspondiente de la Real Academia en Málaga entre 1909 y $1920^{4}$ y primer cronista oficial de la localidad de Ronda, ${ }^{5}$ publicó en el $\mathrm{n}^{0} 63$ del Boletín de la institución; dicha "Memoria" no tenía más fin que informar acerca del estado en que se encontraban las ruinas de la ciudad de Acinippo, ${ }^{6}$ ubicada en el lugar conocido como Ronda la Vieja o Mesa de Ronda la Vieja, perteneciente al actual término municipal de Ronda (Málaga) y enclavado en la Serranía del mismo nombre. ${ }^{7}$

Precedido por un informe de Antonio Blázquez, académico numerario, el cronista da cuenta en el citado trabajo de los diferentes vestigios que él mismo "ha visto y

\footnotetext{
Abascal - Cebrián 2006, 336.

Maier - Salas 2000, 506.

Su nombramiento como cronista oficial de Ronda tuvo lugar en 1908, según se desprende de la documentación conservada al respecto en la propia Real Academia: una carpetilla con el expediente relativo a dicha elección, la carta en que Madrid Muñoz comunica su nombramiento, de 26 de agosto de 1908, y la felicitación cursada con tal motivo por la propia Academia, fechada el 18 de octubre del mismo año (CAMA/9/7962/38/1-3, respectivamente; cf. Maier - Salas 2000, 323).

Una síntesis sobre esta ciudad en época romana en Morales Rodríguez 2002, 43-54, y Campos et alii 2018, 33-36.

Madrid Muñoz 1913, 85-101.
} 
escudriñado en sus repetidas exploraciones al histórico suelo", ${ }^{8}$ enumerando, un tanto a vuelapluma, los despojos arquitectónicos, cerámicos, metálicos, vítreos y las urnas cinerarias, y deteniéndose algo más en las monedas, en las medallas y los bronces, en los epígrafes y, cómo no, en las ruinas del teatro, cuya "principalísima" importancia se destaca. No extraña, en consecuencia, que de las cuatro fotografías con que se completa el trabajo, todas realizadas por el fotógrafo rondeño Martín Sánchez, tres obedezcan a otras tantas vistas del teatro. ${ }^{9}$

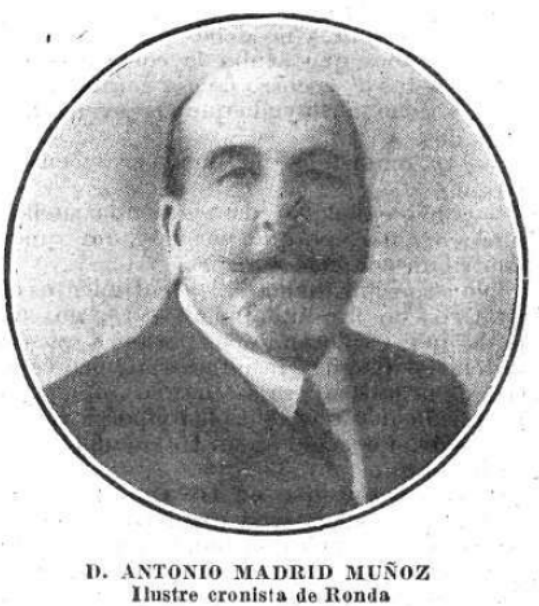

Fig. 1. Retrato de Antonio Madrid Muñoz (Mundo Gráfico, 19 de enero de 1916).

Sin embargo, según tuvimos oportunidad de comprobar al consultar la documentación referente a la signatura 9-7475, y de constatar después con el cotejo del primer volumen del Catálogo de Fotografías de Antigüedades y Monumentos de la Real Academia, ${ }^{10}$ en torno a 1913 Madrid Muñoz había remitido a la Real Academia no sólo cuatro fotografías, sino nueve -todas tomadas por el mismo fotógrafo-, además de las dos láminas ya citadas en las líneas precedentes. Estas láminas contienen dibujos realizados a tinta y coloreados de algunas inscripciones y otros materiales arqueológicos procedentes de Acinippo $;^{11}$ fueron ya numeradas y tituladas por el propio autor, exactamente de la misma manera en que ahora se registran en el inventario de la Academia:

8 Madrid Muñoz 1913, 92. Algunos de estos vestigios fueron coleccionados por el propio autor y, a su muerte, fueron entregados a la Real Academia por su viuda, Teresa Granadino, según consta en un informe original y manuscrito redactado por José Ramón Mélida y firmado en Madrid, en julio de 1921, por el propio Mélida, Antonio Vives y Manuel Gómez Moreno (cf. Gómez Moreno et alii 1921; disponible en http://www. cervantesvirtual.com/nd/ark:/59851/ bmcv13r6, consultado el 17 de febrero de 2020); el informe vería la luz en el $\mathrm{n}^{\mathrm{o}} 79$ del Boletín (Mélida y Alinari et alii, 1921).

9 Las figuras, por orden de aparición son: Ruinas del templo de Marte (o del foro); Teatro romano, vista tomada desde el N; Teatro romano, vista tomada desde el NO; Teatro romano, vista tomada desde el SO. Una buena síntesis sobre este edificio en Ventura Villanueva 2008, 202-208.

10 Sáenz Samaniego - Arbeláez Zapata - Maier Allende 2017, 124-128, nº 218-229.

11 Aunque no sea objeto de análisis en este trabajo, me permito llamar la atención sobre el carnero dibujado en la lámina $n^{\circ} 1$ (véase más abajo la Fig. 4, con el nº 2) y remitir a los trabajos de Rodríguez Oliva 2001-2002, 301-312, y 2003, 330-331; la coincidencia entre las medidas aportadas por Madrid Muñoz al pie de la figura y las que especifica este investigador para la pieza de Teba son, cuando menos, sorprendentes. 
"Dibujos complementarios". Dicho de otro modo, por las razones que fuesen, se excluyeron de la publicación de la "Memoria" dedicada a Acinippo las dos láminas de dibujos y cinco fotografías de las nueve que envió el cronista rondeño: otras dos vistas del teatro, ${ }^{12}$ una panorámica general de la Mesa de Ronda la Vieja, ${ }^{13}$ una instantánea con diferentes restos arqueológicos (una urna cineraria, una cabeza en mármol de carrara y el fragmento de un relieve $)^{14}$ y una fotografía con dos inscripciones. ${ }^{15}$

Esta omisión hubiese carecido de importancia si no fuese porque: primero, algunos de los epígrafes que constan en las fotografías y en los dibujos eran inéditos en su momento; segundo, para algunos de ellos Madrid Muñoz no sólo es la primera, sino la única fuente de que disponemos para conocer su existencia; tercero, hasta donde yo sé, no se conocen otras imágenes de los mismos; cuarto, en los dibujos el autor anotó una serie de datos derivados de su autopsia que no llegaron a integrarse en el texto de la "Memoria" y que, en consecuencia, han permanecido prácticamente ignorados.

Y es que, que nosotros sepamos, al margen de la consignación de las láminas en el trabajo de Abascal y Cebrián y de la inclusión de las fotografías en el Catálogo citado, hasta la fecha no se ha abordado un análisis detallado, de índole epigráfica, de las láminas y de la fotografía. A ese análisis dedicaremos, por tanto, estas páginas.

\section{Los epígrafes anotados por Antonio Madrid Muñoz}

\subsection{El epígrafe conservado en el pavimento de la entrada del cortijo de Ronda la Vieja}

En la citada "Memoria" Madrid Muñoz inicia su breve repaso a la epigrafía de Acinippo señalando que las novedades, por lo que a esta materia se refiere, se limitan al hallazgo de epígrafes de carácter funerario; hecha esta advertencia, abre la serie presentando: "una no catalogada por Hübner, que de antiguo existe á la entrada del cortijo de Ronda la Vieja, empotrada en el suelo, cuya leyenda es:

\section{S SACERDO / F $\cdot$ RVFINA / VS $\cdot$ MARCELLVS $\cdot$ F $/ \cdot$ D"16}

Curiosamente, este epígrafe es el único del que tenemos constancia por otra fuente, pues, en efecto, una década antes había sido reconocido por Charles Dubois, quien lo había presentado, como puede verse en la figura adjunta (Fig. 2), exactamente en el mismo emplazamiento y con lectura prácticamente idéntica: ${ }^{17}$

\footnotetext{
12 En este caso tomadas desde el SO y el SE (Sáenz Samaniego - Arbeláez Zapata - Maier Allende 2017, 125, nº 220 y n 221 , signatura 9-7475-6 y 7, respectivamente).

3 Sáenz Samaniego - Arbeláez Zapata - Maier Allende 2017, 125, no 218, signatura 9-7475-4.

Sáenz Samaniego - Arbeláez Zapata - Maier Allende 2017, 124, n² 217, signatura 9-7475-3.

Sáenz Samaniego - Arbeláez Zapata - Maier Allende 2017, 124-125, no 219, signatura 9-7475-5.

Madrid Muñoz 1913, 94. En todas las citas textuales se respeta la ortografía y puntuación de los originales.

7 Dubois $1901,225, \mathrm{n}^{\circ} 35$.
} 
A Ronda la Vieja, au cortijo de ce nom, plaque encastrée dans le pavage, sous le grand portail intérieur. Les lettres des deux premières lignes sont de 10 centimètres, les autres de 8. L'o de Sacerdo est inscrit dans le $\mathrm{D}$.

\section{S SACERDO \\ F $\cdot$ RVFINA \\ $\mathrm{S} \cdot$ MARCELLVS $\cdot \mathbf{F}$ \\ D.}

Fig. 2. Texto de Dubois 1901, 225.

La inscripción, como fácilmente puede comprobarse, es registrada en las bases de datos epigráficas vinculada de modo exclusivo al trabajo de Dubois y ofrecida siempre en mayúsculas, como si el texto no ofreciese las suficientes garantías, ${ }^{18}$ es quizá esta circunstancia la que explica que los nombres que en ella se transmiten falten en el clásico repertorio antroponímico de Abascal Palazón. ${ }^{19}$ No obstante, el texto es conocido y empleado, como tendremos oportunidad de ver, por los investigadores que han centrado su labor en el estudio de la Bética romana desde diferentes perspectivas.

Nos interesa aquí destacar que, precisamente, este epígrafe aparece en una de las fotografías aportadas por Madrid Muñoz (Figs. 3-4) y, también, en la lámina no 1 de sus Dibujos complementarios, en la que se registra con el $\mathrm{n}^{\circ} 4$ (Fig. 5). Esta feliz circunstancia nos permite describir con precisión el epígrafe y ofrecer, combinando al efecto los datos proporcionados por el cronista rondeño y por Dubois, una edición bastante completa del mismo.

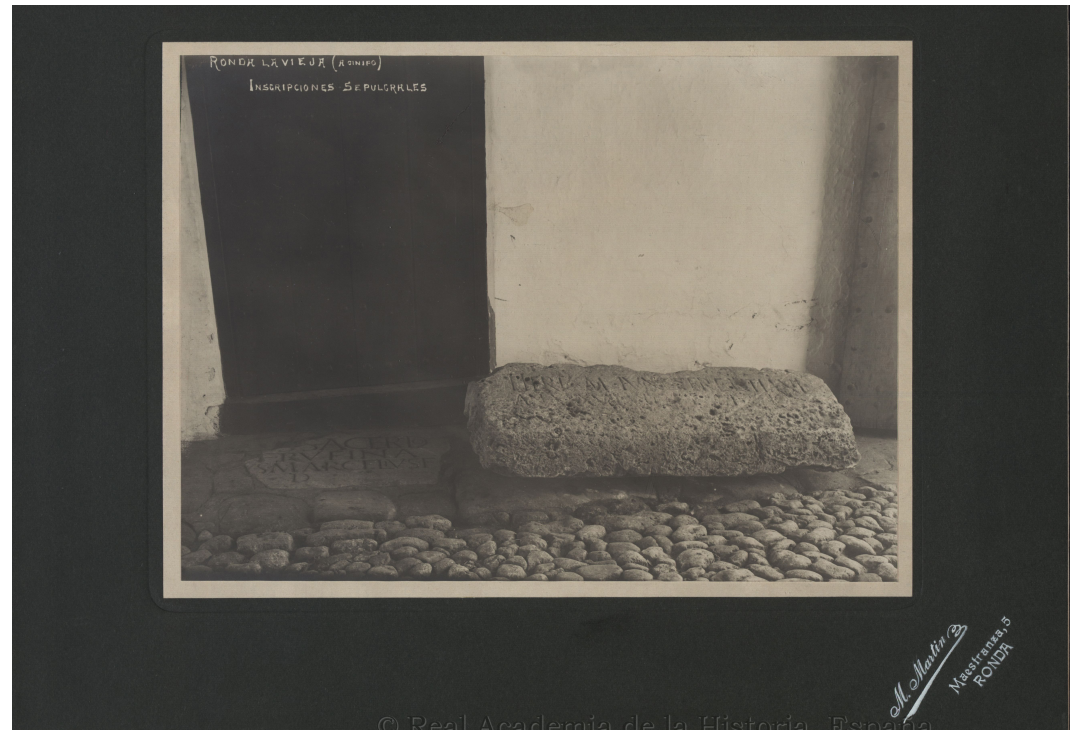

Fig. 3. Epígrafes conservados en la entrada del cortijo de Ronda la Vieja (RAH-9-7475-5; (C) Real Academia de la Historia. España).

Véase HEpOL 25033 y EDCS-74200451.

Abascal Palazón 1994. 
Corresponde el epígrafe al fragmento de una placa de mármol blanco, rota por todos sus lados, ${ }^{20}$ de (77) x (90) x ?:21 presenta unas elegantes capitales cuadradas, bien ejecutadas y dotadas de refuerzos, cuyas medidas oscilan entre los 10 y 8 ; el texto está correctamente puntuado - siempre de acuerdo con Madrid Muñoz y Dubois, pues en la fotografía apenas se perciben- con interpunciones de carácter triangular. En la primera línea conservada la $\mathrm{O}$ aparece incluida en la $\mathrm{D}$ y, en la tercera, la segunda $\mathrm{L}$ inserta en la primera. Presenta una paginación cuidada y centrada y, de acuerdo con la misma, parece posible admitir que no falta texto ni por el lateral derecho ni por la parte inferior. Desconocemos si el epígrafe permanece en el mismo lugar.

Su lectura, por lo demás, no admite dudas y corrobora lo anotado en su momento por Dubois y Madrid Muñoz:

- - - - - / [- - -]s [·?] sacer $\hat{d o}(-?) /[-$ - -] f(ilia) $\cdot$ Rufina $\beta$ [- - -]us · Marcêllus f(ilius) $/[---] \cdot d($ ed-, edicav-)
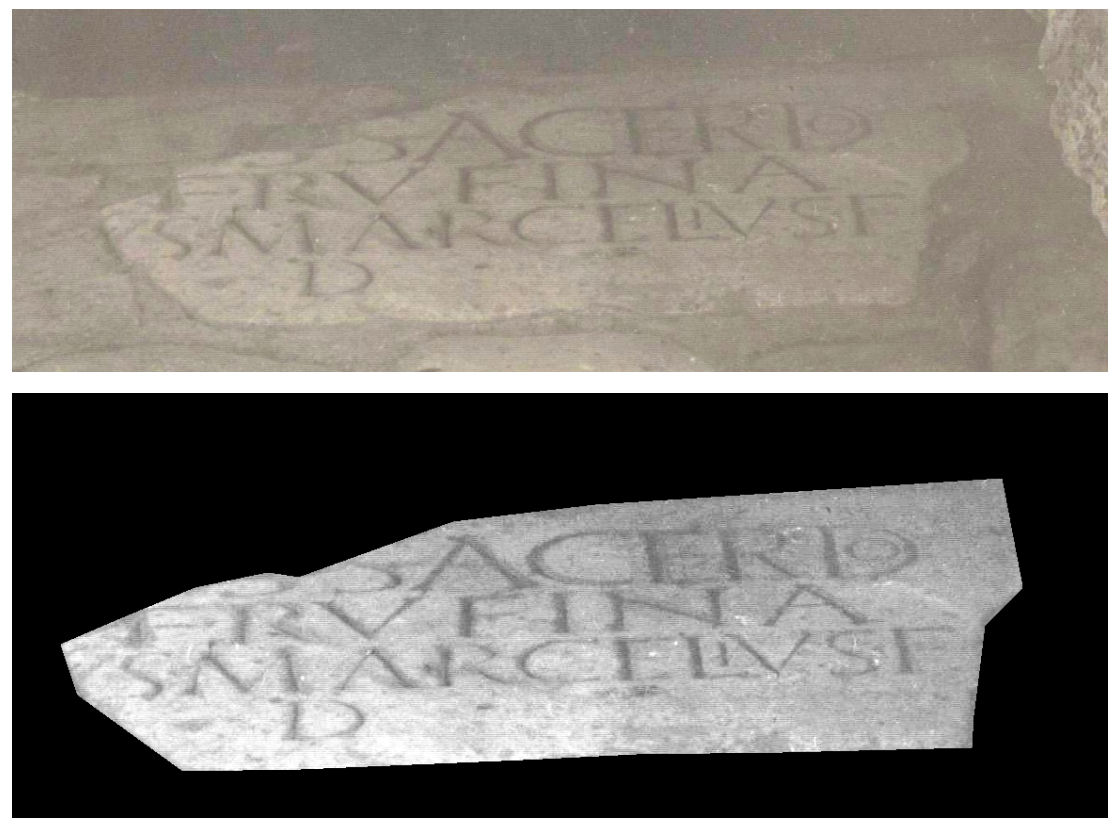

Fig. 4. Arriba: epígrafe correspondiente a HEpOL 25033 - EDCS-74200451, según la fotografía original (RAH-9-7475-5; (C) Real Academia de la Historia. España). Abajo: tras el tratamiento aplicado por Joaquín Gómez-Pantoja.

Como única novedad con respecto a las lecturas previas, anotamos al inicio de la lín. 1 una interpunción que, habida cuenta de la correcta puntuación del texto conservado, parece lícito presumir, si bien resulta patente que la fractura de la pieza comportó su desaparición. En lín. 3 la V inicial no fue vista por Dubois, pero sí por Madrid Muñoz, pudiéndose apreciar en la fotografía la mitad superior de su trazo derecho.

No podemos descartar, sin embargo, que el borde inferior sea el original.

21 Expresamos las medidas siempre en $\mathrm{cm}$. 
La fórmula final, centrada, permite considerar - sin descartar otras opcionesque nos encontramos ante un epígrafe de carácter conmemorativo (¿votivo?, ¿evergético?) en el que aparentemente participan tres individuos: del primero sólo resta la indicación de su cargo sacerdotal -presumiblemente abreviado en la propia línea y sin continuar en la siguiente-y, posiblemente, el final de su cognomen en nominativo; de los dos restantes, una mujer y un hombre, se conserva parte de su filiación y su cognomen (en el caso de la dama) y la parte final de su nomen y su cognomen completo, seguido de la indicación de su parentesco (en el caso del varón).

No hay posibilidad, a la vista de la fotografía, de avanzar propuestas de restitución para los nomina perdidos y, por lo que respecta a los cognomina, Rufina y Marcellus, ambos latinos, poco puede señalarse salvo su vulgaridad. ${ }^{22}$

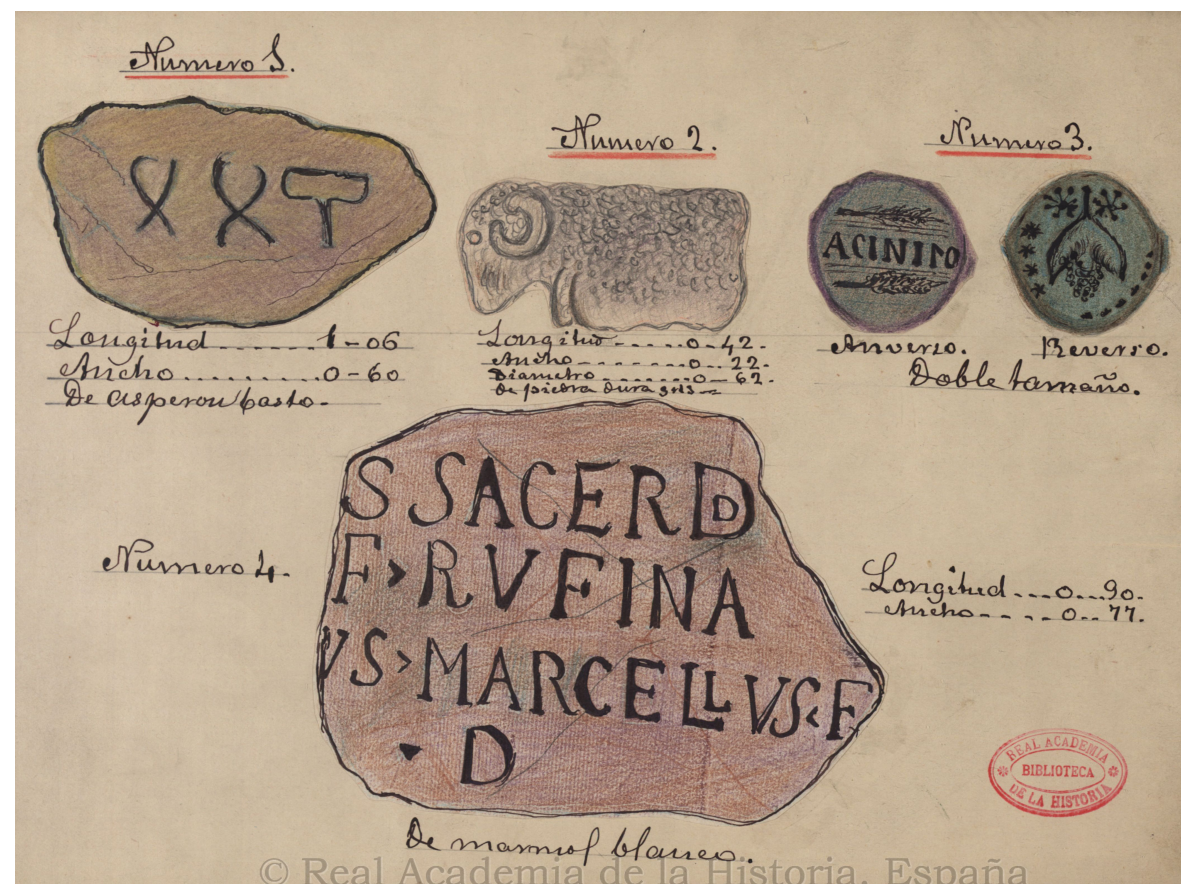

Fig. 5. Epígrafe correspondiente a HEpOL 25033 y EDCS-74200451 según el Dibujo complementario $\mathrm{n}^{\mathrm{o}} 1, \mathrm{n}^{\circ}$ 4, de Madrid Muñoz (RAH-9-7475-1; (C) Real Academia de la Historia. España).

Por lo dicho, resulta cuando menos notable la versión que de este epígrafe hizo Fidel Fita, tal y como señala el propio Madrid Muñoz en su "Memoria"; es la que sigue: "Marco Junio Terenciano Sacerdote y Junia Rufina, hija de Marco, y Junio Marcelo, hijo del mismo, dedicaron este monumento". ${ }^{23}$ De qué material dispuso el padre Fita para llegar a esta completa y sorprendente lectura es extremo que no estamos en condiciones de precisar con certeza; en la Real Academia se conservan documentos fechados en diciembre de 1910 que indican que, en efecto, unas inscripciones romanas de Acinippo, que habían sido previamente enviadas por

\footnotetext{
Véase Abascal Palazón 1994, 413 (Marcellus) y 485-486 (Rufina).

23 Madrid Muñoz 1913, 95.
} 
Madrid Muñoz y que fueron presentadas a la institución por Juan Pérez de Guzmán y Gallo, fueron puestas a disposición del jesuita para la redacción del pertinente informe. ${ }^{24}$ Por la fecha en la que, al menos grosso modo, se fechan las fotografías enviadas por Madrid Muñoz que aquí analizamos (ca. 1913) no podemos afirmar que se trate de las mismas inscripciones; lo cierto es que, al margen del epígrafe relativo a un ladrillo cristiano, ${ }^{25}$ no parece conservarse ningún documento referente a inscripciones rondeñas entre los papeles de $\mathrm{Fita}^{26}{ }^{26}$ ni nos consta que el buen padre publicase las que aquí nos ocupan, aunque sí llegó a mencionar alguna, como veremos.

Cuesta creer, aun conociendo el particular modus operandi del jesuita, ${ }^{27}$ que los complementos a la inscripción -que Madrid Muñoz asumió, pese a la claridad del texto, acatando obediente el criterio de autoridad-saliesen de la nada. ¿Fue el epígrafe correspondiente a CIL II $1347^{28}$ el que sugirió completar la inscripción con el nombre de M. Iunius Terentianus?, ¿fueron los epígrafes que veremos a continuación?, ¿todos ellos de modo conjunto? Bien pudiera ser, ${ }^{29}$ aunque lo cierto es que, puestos a proponer un gentilicio para completar el texto, el nomen Servilius, que es el que portan los dos varones que desempeñaron sacerdocios documentados en Acinippo, ${ }^{30}$ hubiera resultado, si no más, igualmente adecuado.

Sea como fuere, lo cierto es que la versión de Fita ha pasado a la bibliografía específica, tal y como puede comprobarse en el trabajo de referencia sobre la prosopografía bética elaborado por la profesora Carmen Castillo quien, como no podía ser de otro modo, toma el dato del trabajo de Madrid Muñoz. ${ }^{31}$

\subsection{El epígrafe hallado en el Arrabal de Ronda la Vieja}

El segundo epígrafe de que da cuenta Madrid Muñoz en su "Memoria" obedece, según indica, a una pieza exhumada por él mismo en la necrópolis baja del Arrabal, siendo su texto presentado en los siguientes términos:

\section{PL·ERIAM (hedera) IVNI TERENTIANI / AN XXXVI I S E I S T T L}

24 Documentos con la signatura CAMA/9/7962/40(1-2), fechados el 9 y 21 de diciembre de 1910, respectivamente (cf. Maier - Salas 2000, 325).

25 Estudiado en su día por Abascal - Gimeno 2000, 173, fig. 270. En el ya citado volumen del Catálogo de Fotografías de la RAH se recogen otras instantáneas relacionadas con Ronda, aunque no con Madrid Muñoz, datadas en 1910; sólo una corresponde a una inscripción y obedece al mencionado ladrillo (Sáenz Samaniego Arbeláez Zapata - Maier Allende 2017, 126-128, n 226-229, signatura 9-7580-15, para el ladrillo, 11-8333-1-3, para las vistas de Ronda).

26 Al menos, así se deduce de Abascal Palazón 1999.

27 Baste citar aquí a modo de ejemplo, y por su claridad, el trabajo de Gómez-Pantoja - García Palomar, 2014.

28 Procedente también de Ronda la Vieja, conocido desde antiguo (y felizmente reaparecido) este epígrafe honorífico está dedicado a M. Iunius L. f. L. n. Gal. Terentianus Servilius Sabinus que fue IIvir, flamen y pontífice perpetuo de colonia Patricia y patrono de Acinippo, cuya plebs promovió la erección de una estatua en su honor. Al respecto de este personaje véanse, en otros, entre otros, Castillo 1965, 109-110, n 205, y 1993, 91; Melchor Gil 2011a, 123-124, y 2011b, 272-273.

29 De hecho, al Prof. Gómez-Pantoja, buen conocedor del "lápiz rojo" de Fita, no le cabía duda: "La mención de Iun. Terentianus en otro epígrafe del lugar era una tentación demasiado fuerte para Fita", me indicaba en comunicación personal.

30 Cf. CIL II 1346 y 1349; con nuevas restituciones y precisiones de lectura en Castillo 1993, 84, n. 4, y 91, n. 59, respectivamente (de donde $H E p$ 5, 1995, 577-578).

31 Castillo 1965, 109, nº 204. 
Es ésta una de las inscripciones para cuyo conocimiento dependemos en exclusiva de la información aportada por el rondeño. Por fortuna, para su análisis disponemos también de fotografía (Figs. 2 y 6 ) y dibujo, este último integrado en la lámina $\mathrm{n}^{\circ} 2$ de sus Dibujos complementarios, en la que aparece con el n $\mathrm{n}^{\mathrm{O}} 5$ (Fig. 7).
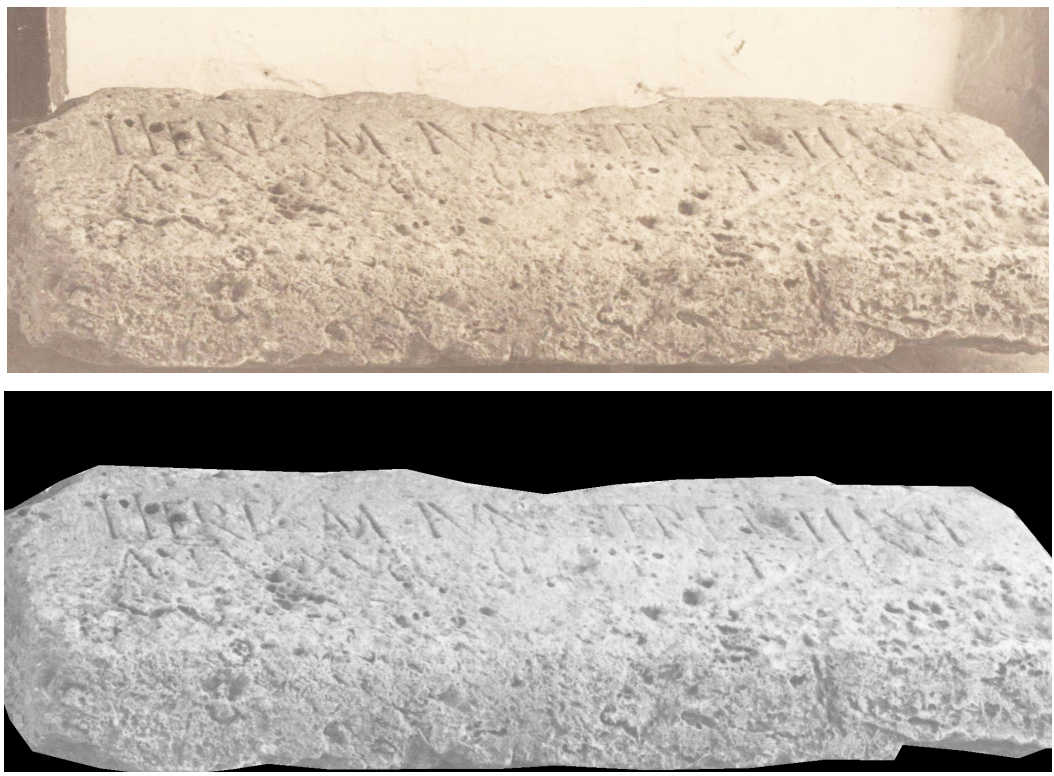

Fig. 6. Arriba: inscripción procedente del Arrabal de Ronda la Vieja, según la fotografía original (RAH-9-7475-5; @ Real Academia de la Historia. España). Abajo: tras el tratamiento aplicado por Joaquín Gómez-Pantoja.

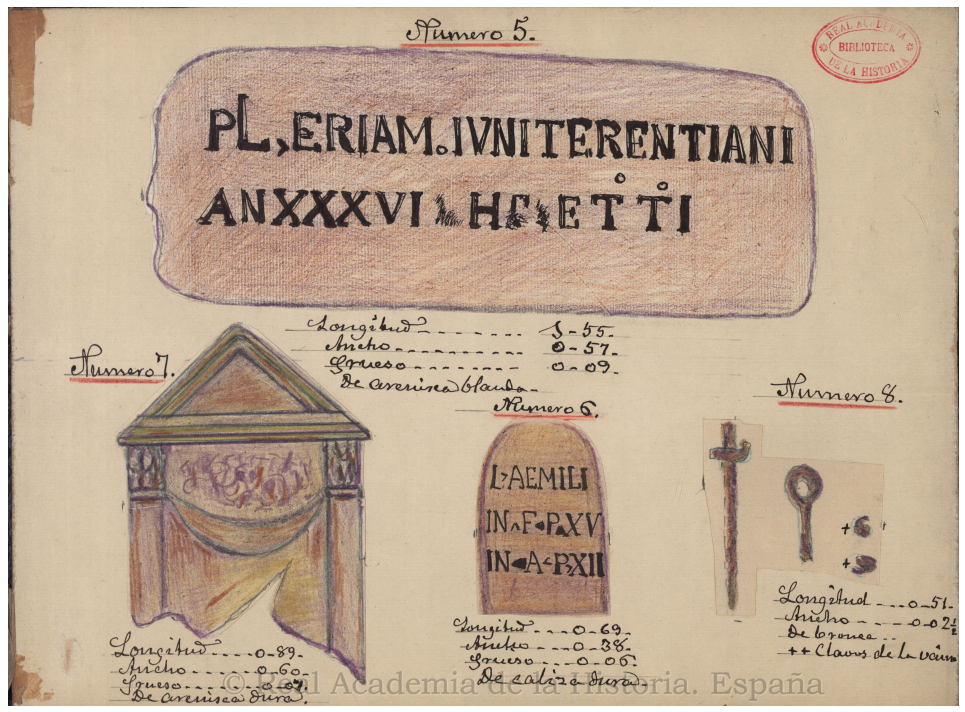

Fig. 7. Dibujo complementario $\mathrm{n}^{\circ} 2$ de Madrid Muñoz; con el $\mathrm{n}^{\circ} 5$ la inscripción procedente del Arrabal de Ronda la Vieja (RAH-9-7475-2; (C) Real Academia de la Historia. España). 
Además, para completar las circunstancias de su hallazgo contamos con el apoyo del artículo que en marzo de 1911, antes de publicar la "Memoria", el propio Madrid Muñoz había editado en el diario La Correspondencia de España; en él narraba, con la prosa propia de la época, dos jornadas de visita al lugar, deteniéndose de modo muy particular en este epígrafe que, según refiere, había encontrado al hilo de una particular "búsqueda del tesoro" -tan espontánea como irregular-1levada a cabo con la ayuda de los lugareños (Fig. 8). No indica el autor la fecha en que cursó tal visita, pero todo hace sospechar que no fue en 1911, sino antes, porque no falta en el artículo de prensa la alusión a la versión que hizo Fita de su lectura, alusión que se repite en la "Memoria"; sí señala, en cambio, que rogó a los naturales conservasen debidamente la memoria exhumada: según se desprende de la fotografía adjunta, el ruego fue atendido, pues en ésta aparece ya colocada a la puerta del cortijo, junto a la inscripción precedente.

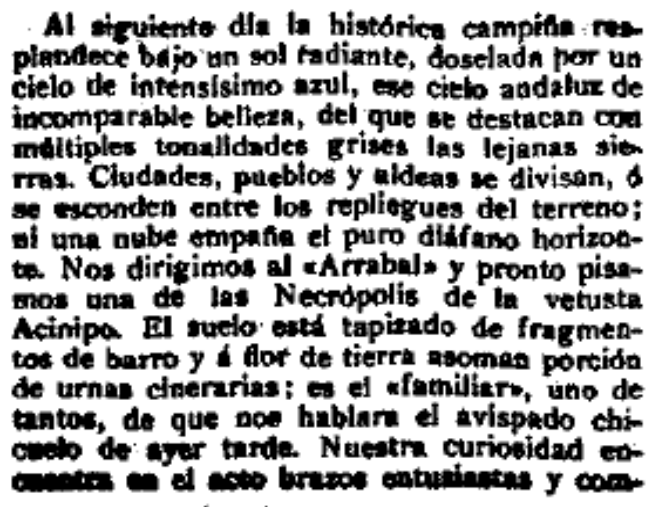

\begin{abstract}
placientes al descubrimiento del resoro, $c$ ideal je siempre. Yronto un enorme sillar abandona su fecho de siglos, dejando al descubierto is urna que sölo conticne aquellos uteasilios guardadores de la moneda afecta al fúnebre transporte. Inmediatamente el crnto de una gran losa tabrada llama la atencióa de los infacigables peones; despojada de $\mathrm{I}_{\mathrm{a}}$ tierra que la cubre, dissele la viteita y se ve «está escritao.
\end{abstract}

Fig. 8. Extracto del artículo de Madrid Muñoz en La Correspondencia de España (1911).

Reuniendo, pues, los datos proporcionados por Madrid Muñoz, podemos decir que la inscripción se halló in situ-¿en su posición original?-en torno al año 1910, en la necrópolis del Arrabal de Ronda la Vieja. ${ }^{32}$ Se trata de una gruesa placa de arenisca blanda, con abundantes oquedades naturales en su superficie, cuyas medidas son 155 x 59 × $9 ;^{33}$ del dibujo parece desprenderse que la pieza se encontró completa, aunque la fotografía muestra, además de la pérdida del ángulo superior izquierdo, un borde superior bastante irregular, sin ser este dato -dadas las características del material y el ángulo de la propia foto- concluyente. Los caracteres del epígrafe corresponden a capitales cuadradas bien ejecutadas, en casos con remates visibles, y, si el ángulo de la instantánea no nos engaña, los de la lín. 2, además de estar muy gastados, parecen sensiblemente menores. Ni en la fotografía ni en el dibujo se advierte la hedera señalada en la "Memoria" tras la M que antecede a IVNI, ni resultan evidentes, a primera vista, otros signos interpunción; mucho nos tememos que, de cara a su

Sobre las necrópolis de Acinippo véanse los trabajos de Castaño - Nieto - Padial 2005 y Nieto 2006, sintetizados en Vaquerizo Gil 2010, 170-173.

33 A la vista de la fotografía, y si el ángulo de la misma no engaña, pudiera haber un error en la consignación de la medida del grosor de la pieza; tomando como base de cálculo las otras dos medidas que, cuando menos, parecen equilibradas, creemos que el grosor rondaría, sin poder precisar más, los $19-20 \mathrm{~cm}$. 
publicación, se pudieron tomar por tales signos los circulitos señalados por Madrid Muñoz en su dibujo, que no son sino las oquedades de la caliza señaladas supra, perfectamente identificables en la fotografía. No obstante, y de no corresponder también a oquedades, podrían considerarse interpunciones circulares los puntos, menos definidos y sombreados, que se advierten en lín. 1, antes y después de la M (Fig. 9).

Vayamos con su lectura. En el artículo de La Correspondencia Madrid Muñoz adelanta ya los datos que aparecerán después en la "Memoria" publicada en el Boletín:

Es una curiosísima muestra de Epigrafía sepulcral. Su versión, que corrige la nuestra, admirablemente hecha por el eminente epigrafista y sabio académico de la Historia, R. P. Fidel Fita, es ésta: «Pulceria, de 36 años de edad, liberta de Marco Junio Terenciano, yace aquí. Séale la tierra ligera». ${ }^{34}$

La misma traducción, en suma, que ofrece el propio Fita en la breve noticia que dedica a dar cuenta del artículo de prensa de Madrid Muñoz, noticia publicada en uno de los números del Boletín de la Academia del año 1911;35 de acuerdo con esta traducción, y siempre según Fita, debía entenderse:

\section{Pulceria M(arci) - Iuni Terentiani l(iberta) / an(norum) XXXVI h(ic) s(ita) e(st) s(it) t(ibi) t(erra) l(evis)}

Como es lógico, y a falta de otras fuentes y datos, es ésta la lectura que, de modo mayoritario, ${ }^{36}$ podemos encontrar en la bibliografía específica, así como en las bases de datos epigráficas y en los repertorios antroponímicos. No hay más diferencia con respecto a la lectura del jesuita que la relativa a la normalización del nombre de la supuesta difunta señalada al inicio de lín. 1: Pulc(h)eria, ${ }^{37}$ un nombre que a fecha de hoy sigue careciendo de paralelos en el registro epigráfico hispano, aspecto éste que ya Fita destacó en su momento.

El nombre del varón, M. Iunius Terentianus, se lee sin dificultad, cierto; sobre él volveremos más adelante. Sin embargo, no creemos que ni el dibujo ni, menos aún, la fotografía, consientan leer Pulc(h)eria o mantener la presencia de una L al final de la misma línea. Si observamos la ampliación adjunta (Fig. 9), al inicio de la lín. 1 el rastro de la "panza" de la $\mathrm{P}$ inicial del nombre, que aparece claramente señalado en el dibujo de la lámina $\mathrm{n}^{\circ} 2$, constituye una especie de "fantasma" muy desvaído que, dada la profundidad de los restantes trazos curvos conservados, ${ }^{38}$ cuesta apreciar y aún admitir. Del mismo modo, es obvio que tras este rasgo inicial no se advierte la L de trazo horizontal prolongado y elegante que consta en el dibujo del rondeño y, desde luego, no hay resto alguno que permita aislar una V. Finalmente, el grupo IA que cerraría el nombre se advierte con extrema dificultad y exige una buena dosis de fe para

\footnotetext{
34 Madrid Muñoz 1911; los mismos datos y lectura en Madrid Muñoz 1913, 94.

35 Fita 1911, 410.

36 Se desmarca de ella Morales Rodríguez 2002, 46, n. 39, que registra el epígrafe tal y como lo ofrece Madrid Muñoz.

37 Véanse, entre otros, Abascal Palazón 1994, 166 (para M. Iunius Terentianus) y 474 (para Pulcheria), así como HEpOL 25877 y EDCS-74300006 para el registro de la inscripción en su conjunto.

38 Compárese, por ejemplo, con las R que siguen en la misma línea.
} 
la admisión de la A, que, aunque ciertamente puede defenderse, resultaría algo más ancha que las restantes, no estaría bien alineada y, además, se aproximaría en exceso a la $\mathrm{M}$ que le sigue, cuando todo apunta a que la paginación del texto es buena. ${ }^{39}$
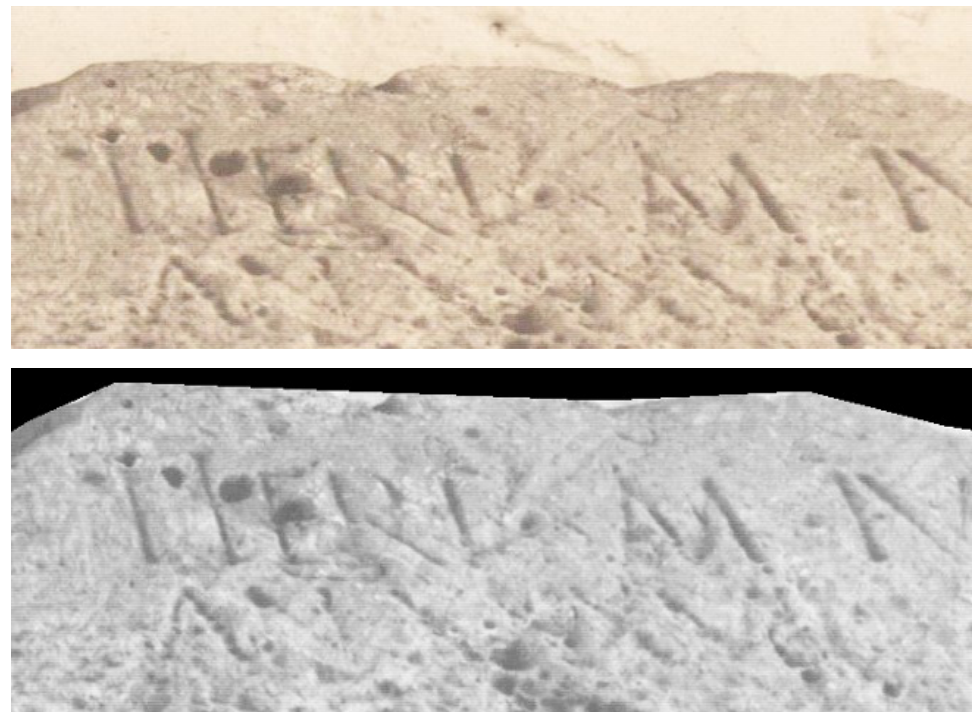

Fig. 9. Arriba: detalle del inicio de la lín. 1 de la inscripción procedente del Arrabal de Ronda la Vieja, según la fotografía original (RAH-9-7475-5; @ Real Academia de la Historia. España). Abajo: tras el tratamiento aplicado por Joaquín Gómez-Pantoja.
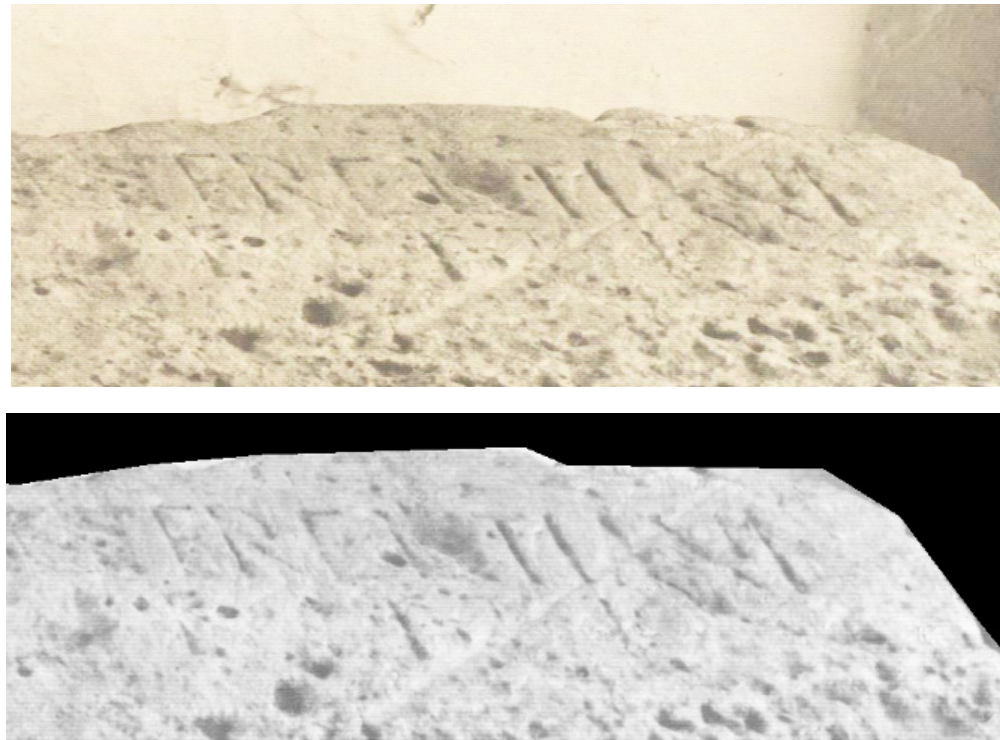

Fig. 10. Arriba: detalle del final de la lín. 1 de la inscripción procedente del Arrabal de Ronda la Vieja, según la fotografía original (RAH-9-7475-5; (C) Real Academia de la Historia. España). Abajo: tras el tratamiento aplicado por Joaquín Gómez-Pantoja.

39 Obsérvense los espacios, regulares, que median entre el praenomen y el nomen y entre éste y el cognomen. 
Si el inicio de la lín. 1, sobre el que luego volveremos, plantea dudas, no creemos ocurra lo mismo con el final, pues la L que, desde Fita, se viene insertando tras Terentiani no parece haya existido nunca: ni aparece en el dibujo de Madrid Muñoz ni se aprecia en la fotografía (Fig. 10); juzgue el lector:

En el inicio del lín. 1 son bien visibles dos trazos verticales, el primero y, sobre todo, el segundo (en cuya correcta percepción no estorba ninguna oquedad) de tamaño notablemente mayor que el resto de las letras de la misma línea; a estos trazos siguen una $\mathrm{E}$ y una $\mathrm{R}$, ambas muy claras, $\mathrm{y}$, a éstas, otro rasgo vertical que bien pudiera corresponder a una I. Cierra la secuencia una serie de trazos de aparente menor profundidad que, a través de la fotografía, no admiten una identificación segura y que no podemos descartar correspondan a heridas de la piedra.

La solución, vistas las incertidumbres que abren y cierran la secuencia inicial de la lín. 1, no es fácil. No obstante, si damos por buena la lectura de Madrid Muñoz para el primer rasgo y admitimos la presencia de una $\mathrm{P}$, cuya panza -insistimos- es apenas perceptible, la secuencia PIERI resultante podría ser asumible, siempre que prescindamos, cierto es, de la A que según el rondeño, cierra el grupo. Podríamos estar, en consecuencia, ante el genitivo del nombre griego Pierus ${ }^{40}$ sin que estorbe en su consideración la I longa que resultaría en la primera sílaba. De ahí, en consecuencia, una primera alternativa de lectura:

\section{Pìeri $\cdot M($ arci) $\cdot$ Iuni Terentiani / an(norum) XXXVI h(ic) ș(it-) e(st) ș(it) t(ibi) t(erra) l(evis)}

De aceptarse esta propuesta, el epígrafe correspondería, muy posiblemente, al epitafio de un esclavo (con el término servus omitido) de M. Iunius Terentianus.

Sin embargo, a la vista de la fotografía creemos que cabe, al menos, otra opción de lectura igualmente plausible. Si admitimos que la secuencia inicial finaliza en IA, como apunta Madrid Muñoz, resulta tentador considerar que los dos primeros rasgos de la línea correspondan en realidad a las astas de una $\mathrm{H}$, cuyo trazo horizontal se ha perdido, con lo que cabría leer HERIA. Si entendemos que, efectivamente, el epígrafe está completo, Heria, con la $\mathrm{H}$ de mayor tamaño, a modo de mayúscula inicial, no sería sino el nombre de la difunta; ésta estaría identificada aquí sólo con su gentilicio y, esencialmente, a través del nombre de su marido; esto es, cabría entender:

Heria M(arci) · Iuni Terentiani (scil. uxor) / an(norum) XXXVI h(ic) ș(ita) e(st) s(it) t(ibi) t(erra) l(evis)

Es una opción sencilla, desde un punto de vista formal y estructural, y muy tentadora, pues nos proporcionaría un nuevo testimonio de una gens cuyo registro epigráfico resulta, tomado en su conjunto, bastante pobre desde un punto de vista numérico. ${ }^{41}$ Herius, que fue en origen un praenomen común en el ámbito oscosabelio, ofrece sus testimonios más antiguos como gentilicio en tierras de samnitas

40 Nombre ya documentado, aunque escasamente, en el registro hispano (cf. Abascal 1994, 458). Lozano Velilla $1998,167$.

41 De no haber errado en nuestro recuento, efectuado a partir de los datos contenidos en EDCS [última consulta realizada el 12 de septiembre de 2019], sólo 39 epígrafes registran este nombre. 
y volscos, para, ya a partir de época protoagustea, extenderse por la Campania. ${ }^{42}$ Decididamente extraño más allá de la fronteras de la península itálica, ${ }^{43}$ interesa de modo especial para nuestro caso el hecho de que, de los cuatro únicos testimonios documentados en Hispania, tres procedan de la Baetica, más concretamente de Italica. ${ }^{44}$

De considerarse que esta alternativa no es sino la lectura correcta, el que aquí presentamos constituiría el segundo testimonio no italiano de este nomen en femenino pues, hasta la fecha, sólo se documentaba en uno de los epígrafes italicenses. Pero no sería éste el único dato relevante. Interesa aquí resaltar que los testimonios hispanos de este gentilicio -en particular el correspondiente a CIL II 1151, de Italica, ${ }^{45} \mathrm{y}$, desde otra perspectiva, el de Cartagena ${ }^{46}$ - parecen permitir intuir el peso de las gentes de procedencia itálica, en este caso campana, en la formación de las élites locales de las comunidades hispanas. ${ }^{47}$

Llegados a este punto creemos que no debe olvidarse que, si bien es cierto que la Serranía de Ronda en su conjunto parece ocupar en época romana una posición un tanto periférica con respecto “al gran triángulo urbanizador que conforma el valle del Guadalquivir", ${ }^{48}$ quizá por su compleja orografía, la estratégica ciudad de Acinippo da muestras de una economía saneada -lo que traduce su potencial y, por ende, su capacidad de atracción- desde fecha temprana. No desde otra perspectiva puede interpretarse su teatro, esa joya privilegiada por Madrid Muñoz en su "Memoria", que se fecha en época de Augusto, ${ }^{49}$ como el de Augusta Emerita, y, por lo mismo, es uno de los más antiguos de Hispania.

Una hipótesis tentadora, sí, pero sólo la localización de la pieza - ¿quién sabe si continúa en el mismo lugar?- permitirá confirmarla. Baste, mientras tanto, con insistir en lo evidente: la lectura de Fita debe desecharse.

\subsection{Un epígrafe más relacionado con M. Iunius Terentianus}

Al hilo del nombre del varón registrado en el epígrafe precedente, prosigue Madrid Muñoz su "Memoria" señalando:

En algún otro lugar aparece también el rastro de Marco Junio Terenciano, el que como antes se dijo, debió ser poderoso magnate y sacerdote principal de la

42 Una magnífica síntesis sobre el origen y difusión este nomen, con los datos conocidos hasta la fecha y la bibliografía que hace al caso, en Barreda Pascual 1998, 208-215.

43 De los 39 epígrafes que registran este nombre 24 proceden de comunidades integradas en la Regio I (Latium et Campania).

44 Son italicenses los epígrafes correspondientes a CIL II 1150 (=ERIt $121=$ CILA 2, 453), CIL II 1151 (=ERIt 119 = CILA 2, $454=$ HEp 15, 2006, 329) y AE 1983, 522 (=ERIt, addenda ad 119, p. $421=$ = CILA 2, 382); el cuarto testimonio procede de Cartagena (HEp 3, 1993, $250=$ DECar $47=E L R H$ C-11).

45 Siempre según la propuesta de Canto: Q(uinti) Her(i) A(uli) l(iberti); datado en época republicana (Canto 1985, 421, en ERIt 119), posiblemente en la segunda mitad del s. I a.C. (Caballos Rufino 2006, 252).

46 [-] Herius C(ai) f(ilius) Hispa [- - ] / leg(atus) pro pr(aetore) pr[ovinciae - - -] (lectura tomada de Díaz Ariño 2008, 101-102, en ELRH C-11), datado por su primer editor entre el 55 y el 49 a.C. (cf. Koch 1989).

47 Véase, para el caso de Italica, la reflexión realizada por Caballos Rufino 2006, 252-254.

48 Ortiz Córdoba 2003, 75.

49 Así Ventura Villanueva 2008, 202-208. Noguera Giménez et alii 2011-2012, 285, indican que no faltan quienes consideren que la fábrica de este edificio debe fecharse antes, entre los años 50-60 a.C., si bien no aportan bibliografía que complemente esta afirmación. 
colonia aciniponense; en un fragmento bastante tosco de otra lápida ha leído este Correspondiente:

OB HONOR M $\cdot \mathrm{I} \cdot \mathrm{TERENTIANI}{ }^{50}$

Lamentablemente, el rondeño no aporta para este epígrafe, para el cual también constituye nuestra única fuente, ningún documento gráfico que pueda venir en nuestra ayuda, por lo que poco podemos añadir a su noticia. Todo lo más que cabe señalar, puesto que no hay motivo para dudar de la veracidad del informante, es que esta inscripción constituiría el segundo testimonio documentado, que no el tercero, ${ }^{51}$ en relación con el mismo individuo; del mismo modo, y como ya señalamos con antelación (véase supra, § 2.1), consideramos muy probable que fuese en este epígrafe, puesto en relación con el analizado en $\S 2.2$ y con el correspondiente a $C I L$ II 1347, en el que se inspiró Fita para completar como completó el primero de la serie, el que precisamente descartamos.

De acuerdo con la simple cita efectuada por Madrid Muñoz, el epígrafe podría desarrollarse como:

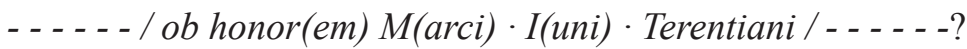

Un repaso al empleo de la fórmula ob honorem en el registro epigráfico, efectuado a través de las bases de datos, ${ }^{52}$ basta para advertir que es muy poco común que vaya seguida, como acontece en este caso, por un nombre personal en genitivo. Lo usual es que tras esta fórmula, cuyo registro es habitual en epígrafes de carácter evergético y votivo-evergético, se inserte el honos obtenido, el mismo que justifica o explica la causa de la donación o dedicación: ${ }^{53}$ se trata, fundamentalmente, de sacerdocios y magistraturas (ob honorem seviratus, flaminatus, pontificatus, aedilitatis, IIviratus, por sólo citar los más frecuentes en el registro hispano), ${ }^{54}$ aunque también la encontramos asociada, en menor medida, a la asunción de la toga viril, ${ }^{55}$ o a la recepción de beneficios tales como la ciudadanía romana ${ }^{56}$ y la immunitas. ${ }^{57}$ No faltan casos, si bien son proporcionalmente menos numerosos, en los que a la fórmula ob honorem sigan los elementos que se donan ${ }^{58} \mathrm{o}$, ya a modo de conclusión, el formulario que expresa la donación. ${ }^{59}$

Del escrutinio realizado en las bases de datos mencionadas se deduce que no se documentan en la epigrafía peninsular textos que presenten la estructura que ofrece el epígrafe rondeño ${ }^{60}$ y que, además, son decididamente escasos en el resto del

\footnotetext{
Madrid Muñoz 1913, 95.

Como ya había indicado Morales Rodríguez 2002, 51.

Fundamentalmente EDCS y HEpOL.

Véase, sobre este particular, Melchor Gil 2005. Cf., igualmente, las reflexiones al respecto de esta fórmula efectuadas por Navarro Caballero 1997, 129-132.

54 A modo de ejemplos, respectivamente, y para el registro hispano: CIL II 1934 (Casares, Málaga), CIL II 1935 (Casares, Málaga), CIL II 1663 (=CIL II²/5, 69, Tucci), CIL II 3423 (=DECar 59; Carthago Nova), CIL II $2 / 5$, 291 (Cisimbrium).

55 Así $A E$ 1994, 345 (Lanuvium).

56 Caso de $C I L \mathrm{II}^{2} / 5,774$ (Singilia Barba).

57 Como CIL XIV 107 (Ostia Antica).

58 Así en CILA 5, 1209 (Morón de la Frontera).

59 Caso de CIL II 3336 (Vivatia).

60 La más similar la encontramos en algunos epígrafes cristianos relacionados con el culto a los Santos, todos los
} 
Imperio. Predominan en este magro conjunto, que muestra una cierta concentración de testimonios en las provincias africanas, los epígrafes de carácter votivo; en ellos se advierte una estructura básica con dos variantes relativas al orden de presentación de sus elementos:

Teónimo + dedicante + fórmula ob honorem + nombre personal en genitivo + parentesco + fórmula de dedicación. ${ }^{61}$

Teónimo + fórmula ob honorem + nombre personal en genitivo + dedicante + parentesco + fórmula de dedicación. ${ }^{62}$

No faltan en este conjunto textos que, por su contenido, más rico en elementos que la estructura básica citada, remitan al "ambiente" en el que, de modo mayoritario, se inserta la fórmula $o b$ honorem; dicho de otro modo, epígrafes que permitan considerar, con mayor o menor certidumbre, que la dedicatoria estuvo efectivamente relacionada con la obtención de un honos por parte del individuo cuyo nombre se registra en genitivo. Baste aquí un ejemplo:

Templ(um) Isis et Serap(is) cum / signis et ornam(entis) et area $\beta$ ob honor(em) MM(arcorum) Porc(iorum) Felicis / et Impetrati f(iliorum) IIIIv(irorum) a(edilicia) p(otestate) de[s(ignatorum)] / M(arcus) Porc(ius) M(arci) l(ibertus) Primig[enius] ${ }^{16}$ mag(ister) Lar(um) Aug(ustorum) re[stituit]. ${ }^{63}$

Vistos estos testimonios, parece posible sospechar -aunque en modo alguno puedan descartarse otras opciones- ${ }^{64}$ que el epígrafe que aquí nos ocupa obedeciese a esa misma estructura y, por extensión, que $M$. Iunius Terentianus desempeñase alguna magistratura o sacerdocio en su comunidad. En esta misma línea podría incidir el nomen que porta, Iunius, ${ }^{65}$ que nos remite a una de las gentes más influyentes de la Bética; ${ }^{66} \mathrm{e}$, incluso, el hecho de que aparezca abreviado, que bien podría explicarse por la circunstancia de que el dedicante - ¿padre, hijo?- lo portaba también y, en consecuencia, podía economizarse.

No está de más, llegados a este punto, recordar que la profesora Castillo sugiere que posiblemente se trate de un antepasado del M. Iunius L. f. L. n. Terentianus Servilius Sabinus documentado en el ya mencionado epígrafe correspondiente a $C I L$ II $1347 .{ }^{67}$

Lamentablemente, no podemos ir más allá; en este caso, Madrid Muñoz no sólo no aportó documento gráfico, sino que ni siquiera indicó en qué sector de la ciudad vio el epígrafe (¿en el foro?, ¿en la necrópolis?), detalle que, quizá, podría habernos ayudado.

cuales siguen la secuencia: ob honorem Sancti ... (así, entre otros: IHC 465, de Santiago de Compostela).

${ }_{61}$ Véase, a modo de ejemplo, el siguiente epígrafe de Ostica Antica (EDCS-51000105): Deo Invicto Mithrae / Diocles ob honorem / C(ai) Lucreti Menandri / patris d(onum) d(edit) d(edicavit).

62 Así: Iunoni / Aug(ustae) / ob honorem Pompei/\{i\}ae Valerinae filiae / Marcus Pompeius / Saturninus et / Valeria Fortuna/ta parentes posuerunt (AE 1946, 50, Banasa).

63 CIL X 7514 (Sulci).

64 Téngase en cuenta que la fórmula $o b$ honorem se constata también, aunque de manera muy minoritaria, en inscripciones de carácter funerario, bien aislada (véase CIL V 5970, de Mediolanum), bien complementada con la secuencia et pietatem (así en CIL II 5254, de la Civitas Coilarnorum).

${ }_{65}$ No faltan ejemplos para ilustrar la abreviatura de este nomen en el registro hispano: así, HEp 4, 1994, 573 (Barbarín, Navarra).

${ }_{66}$ Iunius constituye, además, uno de los gentilicios mejor documentados en Hispania; por su parte, Terentianus, sin ser desconocido, no es un cognomen muy frecuente (cf. Abascal Palazón 1994, 163-166 y 525, respectivamente).

${ }^{67}$ Castillo 1965, 109, nº 204. 


\subsection{El epígrafe funerario de L. Aemilius}

Finaliza Madrid Muñoz su "Memoria", a efectos de novedades epigráficas, dando cuenta del "reciente" hallazgo de un sepulcro puesto al descubierto por la reja del arado en la necrópolis del Arrabal; un sepulcro:

(...) formado por una gran piedra arenisca labrada que le servía de asiento, dos tégulas de mucho grueso á los costados y una portadilla ó templete en caliza fina, de extraordinario gusto, como cubierta, teniendo por almohada ó cabecera otra de la misma clase con el epitafio de Lucio Emilio, que marca los pies del ámbito del monumento.

$\mathrm{L} \cdot \mathrm{A} \mathrm{E} \mathrm{M} \mathrm{I} \mathrm{L} \mathrm{I} / \mathrm{I} \mathrm{N} \cdot \mathrm{F} \cdot \mathrm{P} \cdot \mathrm{XV} / \mathrm{IN} \cdot \mathrm{A} \cdot \mathrm{P} \cdot \mathrm{X} \mathrm{II}{ }^{68}$

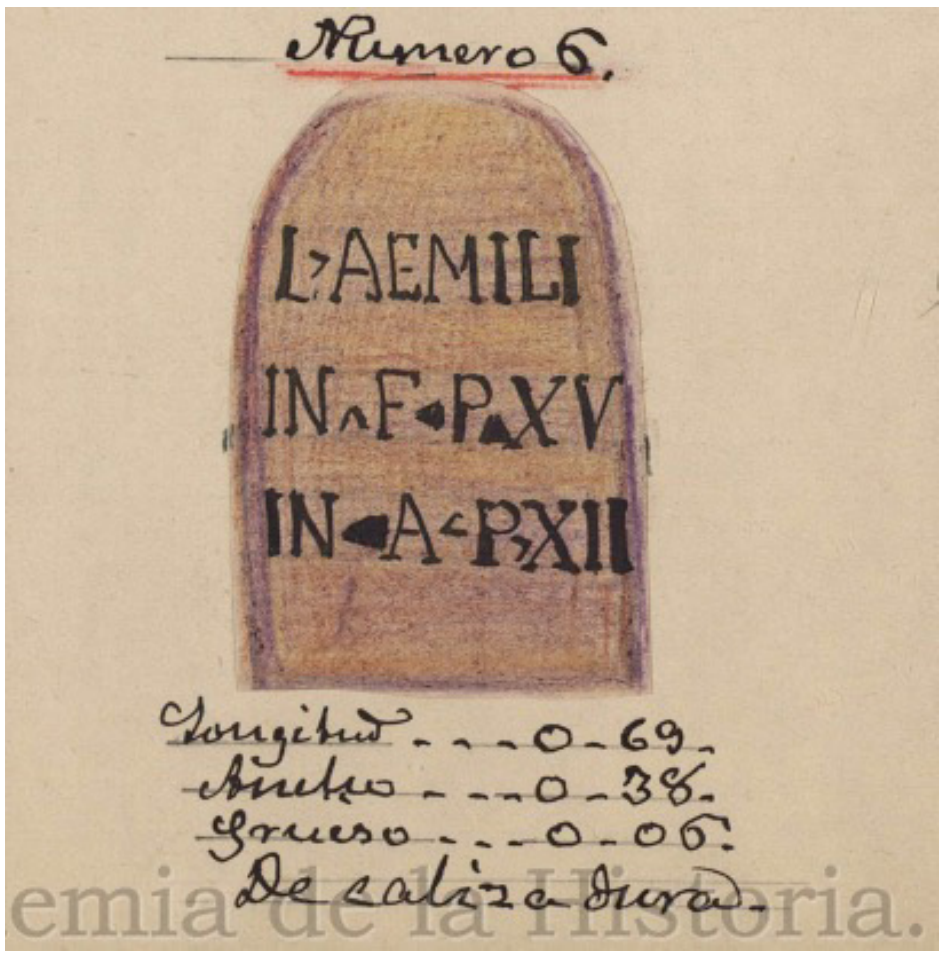

Fig. 11. Detalle del Dibujo complementario $\mathrm{n}^{\circ} 2$ de Madrid Muñoz; $\mathrm{n}^{\circ}$ 6: estela de $L$. Aemilius (RAH-9-7475-2; (C) Real Academia de la Historia. España).

Se trata, también en este caso, de una inscripción que sólo conocemos en virtud de este trabajo y que, pese a ser conocida, tampoco parece haber gozado de una completa difusión. Por fortuna, volvemos a contar con el apoyo de los dibujos aportados por Madrid Muñoz quien, en este caso, incluye en la lámina $\mathrm{n}^{\circ} 2$ de sus Dibujos complementarios la "portadilla o templete" que hacía las veces de cubierta en la sepultura (Fig. 7, $\mathbf{n}^{\mathbf{0}} \mathbf{7}$ ), algunos objetos que formaban parte de su ajuar, como una "espadilla" (Fig. $\mathbf{7}, \mathbf{n}^{\mathbf{0}} \mathbf{8}$ ), y, por supuesto, la inscripción que aquí nos ocupa, que

68 Madrid Muñoz 1913, 95. 
se registra con el $n^{\circ} 6$ (Figs. $7, \mathbf{n}^{0} \mathbf{6}, \mathbf{y}$ 11). Será este dibujo el que permita, en ausencia de fotografía, completar nuestro conocimiento al respecto de sus características físicas.

De acuerdo con dicho dibujo, estamos ante una estela de cabecera semicircular realizada en caliza dura y que, en el momento de su hallazgo, se encontraba en buen estado de conservación -si bien Madrid Muñoz señala que "como se demuestra por los trazos de su facsímile, [la tumba] ha sido roída muchos años por el arado"-y aparentemente completa, midiendo 69 × 38 × 6 . Sus letras parecen capitales de buena ejecución, con refuerzos, y el texto está perfectamente puntuado mediante triángulos.

Su lectura no plantea mayores problemas y no aporta novedades con respecto a lo transmitido en la "Memoria":

\section{$L($ uci $) \cdot$ Aemili $/$ in $\cdot f($ ronte $) \cdot p($ edes $) \cdot X V \beta$ in $\cdot a($ gro $) \cdot p($ edes $) \cdot X I I$}

Nos encontramos, en suma, ante un texto muy sencillo, en el que consta, en genitivo, el nombre del difunto, compuesto por praenomen y nomen, correspondiendo este último a un gentilicio bien conocido en Hispania ${ }^{69} \mathrm{y}$, como bien anota ya Madrid Muñoz, documentado en la propia Acinippo. ${ }^{70}$ Completa el epígrafe la indicación de la pedatura, de las medidas del acotado funerario, indicación que es particularmente característica de la epigrafía funeraria de la Baetica y, especialmente, del conventus Astigitanus. De las medidas señaladas -15 pies hacia la fachada y 12 hacia el fondose deduce una superficie de 180 pies cuadrados o, lo que es lo mismo, de 15,74 metros cuadrados $;^{71}$ se trataría, en consecuencia, de un acotado cuyas dimensiones se encuadran en la horquilla más común dentro del registro epigráfico hispano. ${ }^{72}$

No obstante lo dicho, el dibujo permite completar o perfilar la información relativa al epígrafe que consta en el catálogo elaborado por Desiderio Vaquerizo y Sebastián Sánchez para el conjunto de tituli hipanos con indicación de pedatura. En este catálogo, el epígrafe que nos ocupa, registrado con el $n^{\circ} 106$, se incluye en la tipología I, estelas, pero se ofrece, por razones obvias, sin adscribir a ningún subtipo concreto ${ }^{73}$ gracias al dibujo de Madrid Muñoz podemos ya incluirla en el subtipo I.A.1, correspondiente a las estelas con coronamiento semicircular o redondeado y campo epigráfico liso, el subtipo frecuente en el repertorio hispano (ca. 40\% del total de ejemplares censados).

No creemos que haya obstáculo para considerar que el individuo enterrado fue ingenuo y, en atención al empleo del genitivo en la consignación de su nombre y a la sencillez del texto, creemos que se puede fechar a inicios del s. I d.C., si no antes.

\footnotetext{
Abascal Palazón 1994, 67-72, constando este testimonio en la página 69.

Véanse CIL II 1350, CIL II 1352 y CIL II 1353.

Cf. Vaquerizo Gil - Sánchez Madrid 2009, 313, nº 106, y Vaquerizo Gil 2010, 80, nº 106.

Véanse, a este respecto, y entre otros, los trabajos de Vaquerizo Gil - Sánchez Madrid 2008, 113-116, Vaquerizo Gil 2010, 55, y el más reciente estudio de Henriques dos Reis 2018, 112-113, en el que, sin embargo, falta el testimonio que aquí nos ocupa que, en efecto, no se encuentra registrado ni en HEpOL ni en EDCS.

73 Los propios autores señalan que bajo esa tipología incluyen los ejemplares que "por su mal estado de conservación o las parcas descripciones o noticias que nos han llegado de ellos, sólo podemos definir como «estelas»" (Vaquerizo Gil - Sánchez Madrid 2008, 106, n. 14; el catálogo también puede encontrarse en Vaquerizo Gil 2010, 80).
} 


\section{Conclusiones}

Los diferentes documentos gráficos que Antonio Madrid Muñoz envió a la Real Academia de la Historia como complemento a su "Memoria" sobre Acinippo, que publicaría en el n ${ }^{\circ} 63$ del Boletín de la institución, corrieron una suerte dispar. Mientras que unos, en especial las fotografías del teatro de la ciudad, encontraron acomodo en dicha publicación, otros (cinco fotografías más y dos láminas con dibujos) fueron excluidos de la misma, permaneciendo ignorados hasta hace apenas unos años.

Rescatadas del olvido, las láminas de dibujos y una de las fotografías, unas y otra de muy buena calidad atendiendo a la época ( $c a$. 1913), nos han permitido completar sobre bases más firmes el conocimiento de cuatro inscripciones procedentes de Ronda la Vieja, para tres de la cuales, conviene no olvidarlo, Madrid Muñoz constituye su primer y único transmisor.

El interés de estos documentos radica no sólo en el hecho de que proporcionan datos valiosos y desconocidos relativos a las características físicas de las inscripciones, sino también, y ello no es menos importante, en que permiten afirmar o cuestionar, según casos, las lecturas que se habían transmitido, en especial las de aquéllas que habían pasado por el singular tamiz del padre Fita.

\section{Referencias bibliográficas}

Abascal, J. M.

(1994): Los nombres personales en las inscripciones latinas de Hispania, Murcia.

(1999): El P. Fidel Fita y su legado documental en la Real Academia de la Historia (=Real Academia de la Historia. Publicaciones del Gabinete de Antigüedades, Antiquaria Hispanica 2), Madrid.

Abascal, J. M. - Cebrián, R. (2006): Manuscritos sobre Antigüedades de la Real Academia de la Historia (=Real Academia de la Historia. Publicaciones del Gabinete de Antigüedades, Antiquaria Hispanica 12), Madrid.

Abascal Palazón, J. M. - Gimeno, H. (Velázquez, I., col.), (2000): Epigrafía hispánica (=Real Academia de la Historia. Publicaciones del Gabinete de Antigüedades, Catálogo del Gabinete de Antigüedades. I. Antigüedades. I.1.2), Madrid.

Abascal Palazón, J. M. - Ramallo Asensio, S. F. (1997): La ciudad de Carthago Nova: la documentación epigráfica, Cartagena $(=D E C a r)$.

Barreda Pascual, A. (1998): Gentes itálicas en Hispania Citerior (218-14 d.C.). Los casos de Tarraco, Carthago Nova $y$ Valentia, Tesis doctoral, Universitat Autònoma de Barcelona.

Caballos Rufino, A. (2006): "Implantación territorial, desarrollo y promoción de las elites de la Bética", [en] A. Caballos Rufino - S. Demougin (eds.), Migrare. La formation des élites dans l'Hispanie romaine (=Ausonius Éditions. Études 11), Bordeaux, 241271.

Campos, J. M. et alii (2018): "El mundo urbano de la Bética. Breve síntesis de las ciudades de los Conventus Hispalensis y Astigitanus", [en] J. M. Campos Carrasco - J. Bermejo Meléndez (eds.), Ciudades romanas de la provincia Baetica. Corpus Vrbium Baeticarum: Conventus Hispalensis et Astigitanus. CVB I, Huelva, vol. II, 29-338.

Canto, A. (1985): Epigrafia romana de Itálica, Tesis doctoral, Universidad Complutense de Madrid (=ERIt). 
Castaño, J. M. - Nieto, B. - Padial, J. (2005): “Intervención arqueológica en la necrópolis iberorromana de Acinipo. Aproximación al ritual funerario en época romana", Cuadernos de Arqueología de Ronda 1, 103-114.

Castillo, C.

(1965): Prosopographia Baetica, Pamplona, 2 vols.

(1993): "Los pontífices de la Bética", [en] Religio deorum: Actas del coloquio internacional de epigrafia Culto y sociedad en Occidente, Sabadell, 83-93.

Díaz Ariño, B. (2008): Epigrafia latina republicana de Hispania (=Universitat de Barcelona. Col·lecció Instrumenta 26), Barcelona (=ELRH).

Dubois, Ch. (1901): “Inscriptions latines d'Espagne”, Bulletin Hispanique 3, 209-225 (https://doi.org/10.3406/hispa.1901.1272).

Fita, F. (1911): "Noticias", Boletín de la Real Academia de la Historia 58, 408-412.

Gómez Moreno, M. - Mélida y Alinari, J. R. - Vives y Escudero, A. (1921): Inventario de la colección de antigüedades procedente de Ronda (Málaga), Real Academia de la Historia, Ms. GA 1921/1.

Gómez-Pantoja, J. L. - García Palomar, F. (2014): "El lápiz rojo del P. Fita”, [en] I. Velázquez - J. Martínez (eds.), Realidad, ficción y autenticidad en el Mundo Antiguo: La investigación ante documentos sospechosos (=Antigüedad y Cristianismo XXIX, 2012), Murcia, 107-116.

Henriques dos Reis, S. (2018): "Epigrafia funerária na Hispania romana: uma revisão à prática da indicatio pedaturae nos tituli sepulcrales", Conimbriga 57, 97-138 (https://doi. org/10.14195/1647-8657_57_3).

Hübner, E. (1869): Corpus Inscriptionum Latinarum II. Inscriptiones Hispaniae Latinae, Berlin (=CIL II).

Koch, M. (1989): “Ein neuer Beamtenamme aus dem republikanischen Hispanien”, Chiron 19, 27-35.

Lozano Velilla, A. (1998): Die griechischen Personennamen auf der iberischen Halbinsel, Heidelberg.

Madrid Muñoz, A.

(1911): “Acinipo (Ronda la Vieja)”, La Correspondencia de España, 21 de marzo, s.p.

(1913): “Acinipo (Ronda la Vieja). Memoria escrita para la Real Academia de la Historia por su correspondiente D. Antonio Madrid Muñoz, cronista de Ronda", Boletín de la Real Academia de la Historia 63, 92-101.

Maier, J. - Salas, J. (2000): Comisión de Antigüedades de la Real Academia de la Historia. Andalucía. Catálogo e índices (=Real Academia de la Historia. Publicaciones del Gabinete de Antigüedades. Catálogos del Gabinete de Antigüedades, Documentación IV.4.7), Madrid.

Melchor Gil, E.

(2005): "Pollicitationes ob honorem y ob liberalitatem en beneficio de una res publica: su reflejo en la epigrafía latina", Revista general de derecho romano 5, s.p. [revista digital: www.iustel.com].

(2011a): "Movilidad geográfica de las élites locales de la Bética", [en] J. M. Iglesias Gil A. Ruiz Gutiérrez (eds.), Viajes y cambios de residencia en el mundo romano, Santander, 119-153.

(2011b): "Élites supralocales en la Bética: entre la civitas y la provincia", [en] A. Caballos Rufino - S. Lefebvre (eds.), Roma generadora de identidades. La experiencia hispana (=Collection de la Casa de Velázquez 123), Madrid, 267-300.

Mélida y Alinari, J. R. - Gómez Moreno, M. - Vives y Escudero, A. (1921): "Nota de la 
colección de antigüedades, procedentes en su mayor parte de Ronda (Málaga), donada a la Academia por la Sra. Doña Teresa Granadino, en cumplimiento de la voluntad de su difunto esposo D. Antonio Madrid Muñoz, nuestro Correspondiente", Boletín de la Real Academia de la Historia 79, 89-90.

Morales Rodríguez, E. Ma (2002): Los municipios flavios de la Bética, Tesis doctoral, Universidad de Granada.

Navarro Caballero, M. (1997): “Les dépenses publiques des notables des cités en Hispania Citerior sous le Haut-Empire", Revue des Études Anciennes 99, 109-140 (https://doi. org/10.3406/rea.1997.4680).

Nieto, B. (2006): "El mundo romano en la depresión natural de Ronda", [en] B. Nieto - J. M. Castaño - J. Padial, Historia de Ronda. Desde la Romanización a la época musulmana, I Congreso de Historia de Ronda, Ronda, 11-131.

Noguera Giménez, J. F. et alii (2011-2012): “Teatros romanos de Hispania: introducción a su estado de conservación y criterios de restauración”, Arché 6-7, 383-390.

Ortiz Córdoba, J. (2013): "Las ciudades romanas de la Serranía de Ronda: Fuentes para su estudio", Arqueología y Territorio 10, 73-86.

Rodríguez Oliva, P.

(2001-2002): "Sobre las esculturas ibéricas e ibero-romanas de los territorios malacitanos", Anales de Prehistoria y Arqueología de la Universidad de Murcia 16-17, 301-320. (2003): "Esculturas zoomorfas de época romano-republicana de la provincia de Málaga", Mainake 25, 321-357.

Sáenz Samaniego, S. - Arbeláez Zapata, A. L. - Maier Allende, J. (2017): Catálogo de Fotografías de Antigüedades y Monumentos. Volumen I. Real Academia de la Historia, Madrid.

Sánchez Madrid, S. - Vaquerizo Gil, D. (2009): “La indicación de la pedatura en tituli sepulcrales hispanos. Estado de la cuestión y nuevas perspectivas", [en] Espacios, usos y formas de la epigrafia hispana en épocas antigua y tardoantigua. Homenaje al Dr. Armin U. Stylow (=Anejos de AEspA XLVIII), Mérida, 331-347.

Stylow, A. U. et alii (eds.), (1998): Corpus Inscriptionum Latinarum II: Inscriptiones Hispaniae Latinae, ed. altera, pars V. Conventus Astigitanus, Berlin-New York $(=C I L$ $\left.\mathrm{II}^{2} / 5\right)$.

Vaquerizo Gil, D. (2010): Necrópolis urbanas en Baetica (=ICAC. Documenta 15), Tarragona. Vaquerizo Gil, D. - Sánchez Madrid, S.

(2008): "Entre lo público y lo privado. Indicatio pedaturae en la epigrafía funeraria hispana", Archivo Español de Arqueología 81, 101-131 (https://doi.org/10.3989/ aespa.2008.v81.42).

(2009): “Addendum al vol. 81 AEspA 2008: Entre lo público y lo privado. Indicatio pedaturae en la epigrafía funeraria hispana", Archivo Español de Arqueología 82, 311313 (https://doi.org/10.3989/aespa.2008.v82).

Ventura Villanueva, Á. (2008): “Edificios de espectáculos: teatros”, [en] P. León (coord.), Arte romano de la Bética I. Arquitectura y urbanismo, Sevilla, 172-221. 